\title{
Moderation Effect of Gender on Relationship between Community of Inquiry and Perceived Learning in Blended Learning Environments
}

\author{
Rouhollah Khodabandelou, Habibah Ab Jalil, Wan Zah Wan Ali, \& Shaffe bin Mohd Daud \\ Universiti Putra Malaysia, Malaysia
}

\begin{abstract}
It is conceivably important that demographic variables such as gender may have an impact on community of inquiry (Col) and perceived learning. This study is in response with Garrison et al. (2010) who suggest that there is a need to determine moderation effects of gender on the relationship between Col elements and perceived learning. A total of 348 undergraduate students were drawn from blended programs in three public universities in Malaysia to be the sample of the study. As research instrumentation, participation in online and face to face session, the community of inquiry questionnaire, and a perceived learning scale were distributed among the respondents. All the questionnaires were validated by a panel of experts, reliability of the instrument was tested in a pilot study and assumptions of Structural Equation Modeling (SEM) were checked before analyzing the data. The findings of the study have shown that although differences between the two groups of undergraduate students (male and female) were statistically significant, the amount of differences were not enough to moderate the relationship between Col components and perceived learning in undergraduate blended learning environments. However, the findings indicate that differences between the two groups of undergraduate students (male and female) were statistically significant.
\end{abstract}

Keywords: Community of Inquiry; Blended Learning Environment; Perceived Learning; Gender; Higher Education

\section{Introduction}

Scholars have worked extensively to develop a structural framework from which to examine online and blended educational experiences. One example, the Community of Inquiry (Col) model, has great potential to serve as such a framework which educators can use for evaluating and assisting in the development of online and blended courses (Garrison \& Arbaugh, 2007). Garrison and Vaughan (2008) used Col to describe, investigate, and research blended learning.

Evidence indicates that $\mathrm{Col}$ is a key factor in creating an effective environment for online and blended learning. As Vaughan (2010) indicates Col is a common framework that directs attention to the process of constructing and confirming deep learning. Garrison et al (2000) emphasized that it is vital to understand the characteristics of learning community that support critical discourse and a valuable learning experience for educational institutions. They have argued that a community of inquiry is important to support critical thinking and meaningful learning in online learning environments. Historically, Swan and Ice (2010) indicate 
that Col is social constructivist in nature and is grounded in John Dewey's (1938) notion of practical inquiry. "The elements of a community of inquiry can enhance or inhibit the quality of the learning experience and learning outcomes" (Garrison et al., 2000 p. 92). Furthermore, the fundamental perspective of the model reflects a "collaborative constructivist" view of teaching and learning which is associated with Dewey's work. Central assumption of Col is that a worthwhile learning experience can be achieved through interaction of three elements of the Col model. Through interplay among the three presence elements, students construct new knowledge in a community of inquiry context. Therefore, Col assumes that learning arises through the communication of these three core components. The elements of Col are namely: cognitive presence, teaching presence, and social presence. Garrison (2003) claimed that the successful learning experience is related with the balance of these elements.

Cognitive presence is one of the elements of the community of inquiry model (Garrison et al., 2010). According to Bentz (2009), cognitive presence is necessary in the establishment and maintenance of cognitive learning. Cognitive presence is defined by Garrison and Anderson (2003) as the ability to construct and validate meaning through reflection and discourse. Within a virtual environment such as a blended class, cognitive presence represents the level by which a student is attentive and actively processing or employing critical thinking skills. It is this component of critical thinking that the categories (phases) of cognitive presence in community of inquiry framework consist of triggering event, where some issue or problem is identified for further inquiry; exploration, where students explore the issue both individually and corporately through critical reflection and discourse; integration, where learners construct meaning from the ideas developed during exploration; and resolution, where learners apply the newly gained knowledge to educational contexts or workplace settings (Arbaugh, 2007).

Teaching presence is the other component of Col that is related to teaching practices and the instructor's role in the blended learning environment (Garrison et al., 2000). Garrison (2007) emphasized the importance of teaching presence by stating "interaction and discourse play a key role in higher-order learning but not without structure (design) and leadership (facilitation and direction)" (p. 67). Hence, it can be claimed that teaching presence is the ability of the instructor or facilitator to develop a close connection with the students in learning environment while overcoming the lack of physical presence accompanying with the online learning environment (Garrison et al., 2000). Therefore, teaching presence in Col refers to the instructor role in the blended learning environments. Teaching presence has three interrelated components: instructional design and organization, facilitating discourse, and direct instruction. The, instructors' roles can be observed through course design, facilitation, and instruction in learning contexts. Moreover, these three elements consider teaching presence to be a balancing factor between the other two presences (social and cognitive) within a community of inquiry.

Social presence is the third constitutive component of Col. Literature has documented the importance of the social presence as an essential component in improving students learning (Tu, 2002). Moreover, social presence helps to facilitate student involvement in learning environment (Krish, Maros, \& Stapa, 2012). Furthermore, the lack of social presence may lead to more frustration and less effective learning. Social presence is also regarded as significant element of supporting learning process and student outcomes. Social presence has three interrelated elements which are affective expression, open communication, and group cohesion (Garrison et al., 2000). The worth of social presence is to create a shared sense of community between students and instructors as well as students and students through 
interactivity in communications. According to its significant role in the learning process and students' outcomes, social presence is worth studying.

Since students' learning is a very broad concept, its application should be narrowed down. In contrast to grades, another approach to measuring students' learning is perceived learning that measures students' perceptions about their own learning. Lewis (2011) stated that perceived learning is the extent to which students recognize that they have obtained new knowledge. Perceived learning is the point of view that a student has concerning the learning that has taken place. Alavi, Marakas, and Yoo (2002) describe perceived learning as "changes in the learner's perceptions of skill and knowledge levels before and after the learning experience" (p.406). Perceived learning is a valid measure of students' learning (Rovai et al., 2009; Rovai, Wighting \& Lucking, 2004).

Corrallo (1994) noted that "there is a considerable literature concerned with establishing the validity of student self-reports about cognitive outcomes" (p. 23). He concludes that perceived learning is a comprehensive indicator of students' learning. Today, perceived learning is used as the principal data source for measuring program success. Therefore, exploring the perceptions of students is sought to ensure quality of the learning experience

It is conceivably important that demographic variables such as gender may have an impact on Col and perceived learning (Gibson et al., 2012; Shea, Sau-Li, \& Pickett, 2006). For example, previous research indicates that there is a relationship between gender and Col elements (Garrison, et al. 2010). Shea et al. (2006) also found gender as a significant predictor of learning community. Other studies highlight the role of gender as a link between Col and perceived learning. They believe that gender plays a moderating role in the relationship between Col components and students' perceived learning (Patrizi, 2010; Rovai \& Baker, 2005).

While demographic variables such as gender appears to play a role in students' community of inquiry, a review of literature shows that little empirical evidence has begun to point relationship between $\mathrm{Col}$, and perceived learning in blended learning environments where gender plays a moderating role. Moreover, Garrison et al. (2010) suggest that there is a need to determine moderation effects of gender in the relationship between Col components and perceived learning because the review of literature shows that there is little research which has looked into the relationship between Col components and perceived learning where gender plays a moderating role. In other words, it is unclear whether gender has a moderation effect on the relationship between Col elements and perceived learning in undergraduate blended learning environment in order to increase student success.

Based on the above discussion, the researchers are interested to conduct the current study. While there is literature to support economic advantages and issues of equity afforded by blended learning, there is unequal amount of empirical evidence of investigating the moderating role of gender on the relationship between Col presences and perceived learning (Hannafin, Hill, Oliver, Glazer, \& Sharma, 2003). Having due consideration, better gender differences in students' perception of Col presences and their learning, instructors will know how to improve the learning process for students in terms of gender (Ong \& Lai, 2006). Therefore, studies focusing on student characteristics as factors in student success are seriously needed. Hence, the main objective of the current study is to examine moderation effects of gender on the relationship between Col and perceived learning in blended learning environments in Malaysian higher education institutions. 


\section{Gender and Community of Inquiry}

Gender is an issue for research on community of inquiry in blended learning environments. Previous research has confirmed that gender is a significant predictor of learning community (Shea et al., 2006). Moreover, it has been identified that the role of gender as a link between Col and perceived learning (Patrizi, 2010; Rovai \& Baker, 2005). Some research has shown that, gender is a significant predictor of community of inquiry (Shea \& Bidjerano, 2009b; Shea et al., 2006). However, there is an inconsistency with this argument. For example, Garrison et al. (2010) addressed that predicted effects of gender on Col is not confirmed. The existing accounts fail to resolve the contradiction between gender and Col. Therefore, there is a need for more studies to investigate the relationship between gender and Col components comprehensively. Garrison et al. (2010) have shown that community development in educational situations includes an attempt to determine how online and blended learning promotes a community of inquiry for students. Hence, some issues such as perceptions of communities and gender have been examined. Some previous work has found that gender is an important factor in the development of community of inquiry in online and blended learning environment (e.g., Rovai \& Baker, 2005; Shea, 2006). In an example, Shea (2006) has found that gender plays a role in community of inquiry. Other researchers have found no difference by gender (Garrison et al., 2010; Lord \& Lomicka, 2008).

Previous studies have confirmed that not only is there a gender imbalance in online instruction, the perceived benefits of participation differ across gender. For instance, Rovai and Baker (2005) have shown that women are more social than men in blended learning environment. Such differences may result in a difference in central components of community of inquiry in learning environment.

Garrison et al. (2010) have examined potential influence of student gender on Col components. They found that although gender play a role in the relationship among Col components but this role is not statistically significant. It can be concluded that, while gender appears to play a role in students' community of inquiry, a review of literature shows that little evidence based on more recent studies have begun to point to the link between Col and gender. Therefore, based on Garrison et al. (2010) suggestion, the current study is going to determine moderation effects of gender in the relationship between Col elements and perceived learning in a large scale study.

\section{Gender and Perceived Learning}

Gender based differences in performance and learning have long been recognized as an important focus for research (Rovai \& Baker, 2005; Yukselturk \& Bulut, 2009). In relation with gender and perceived learning there have been different results. For example, Sullivan (2001) has analyzed higher education students' experiences in online environment by gender differences. The result of the study has shown that there are significant differences between male and female students in perceived learning. Moreover, Taplin and Jegede (2001) confirm that gender differences contribute to success in online education. Another study by Price (2006) has found that there are differences in academic engagement by male and female students in online environment. In addition, Gunn, McSporran, Macleod, and French (2003) mention that there are gender differences in blended learning environment. 
However, in a meta-analysis, Astleitner and Steinberg (2005) have shown that the data for investigating the effects of gender in web based learning are insignificant. In another study, Lu, $\mathrm{Yu}$, and Liu (2003) have found that gender does not have any significant impact on students' learning. Later, Yukselturk and Bulut (2007) found that gender variable was unrelated to students' learning in blended course. In summary, according to these studies, there are conflicting findings with regard to relationships between gender, perceived learning, and community of inquiry in the literature and there is need more studies.

Based on the above explanation, it can be concluded that there is a large volume of published studies examining the relationship between gender and students' learning in online and blended learning environments. These studies have confirmed that gender plays an important role in students' learning especially in blended and online learning environments (Ong \& Lai, 2006). This implies that efforts should be made to examine the relationship between gender and perceived learning in blended learning environments.

\section{Method}

\section{Sample}

The sample used in this study $(n=348)$ was drawn from blended undergraduate students participating in three public universities in Malaysia. A random sample of students was requested to complete the survey when they participate in their face to face meeting. The data were collected from January 11, 2013 to February 20, 2013. The gender distribution of the sample was $38 \%$ male and $62 \%$ female. Respondents were asked to indicate their ethnicity status as well. Approximately $71 \%$ were Malays, $21 \%$ were Chinese, and only $4 \%$ were Indian. In terms of using internet status, $38 \%$ of respondents were using internet 2 to 5 hours per day, while only $3 \%$ of them are using internet less than one hour. Of the 348 respondents, $34 \%$ identified themselves to be in semester $3,25 \%$ in semester 4 , and $24 \%$ in semester 5 . While only $17 \%$ reported themselves as semester 6 students.

\section{Instrumentation}

For the purpose of this study, three surveys were used as the instruments. These include student's Col Survey Instrument: this contains three questionnaires (social presence, cognitive presence and teaching presence), and perceived learning. Additionally, students' demographic information such as gender and age were collected. The Col surveys were modified from Arbaugh et al., (2008), Shea and Bidjerano (2009b), Garrison et al., (2010), and Kim (2011) for their research examining social presence, cognitive presence, and teaching presence within blended learning environment.

Social presence survey contains 17 items, in which eight items were for affective expression, five items for open communication, and four items for group cohesion. Teaching presence survey contains 21 items, in which seven items were for design and organization, seven items for facilitating discourse, and seven items for direct instruction subscales. The cognitive presence survey contains 22 items, in which six items were for triggering event, five items for resolution, five items for exploration, and six items for integration. 
The surveys utilized a five point Likert scale. For perceived learning questionnaire the items were modified from the CAP Perceived Learning Scale created by Rovai et al. (2009), and the perceived learning achievement scale (Kim, 2011). The current study's instrument has 19 items with 7 Likert-scale from $0=$ not at all to $6=$ very much so. The Cronbach's Alpha coefficient was used to test internal consistency. Perceived learning construct was considered to be a reliable factor with an alpha level of 0.89 . The social presence and cognitive presence constructs were found to be a strong and highly reliable factor with an alpha level of 0.85 for both constructs. The teaching presence variable was found to be strong reliable factor with an alpha level of 0.87 .

\section{Data Gathering}

After acquiring the relevant permissions, the data collection process began with surveying sample students. In total, 448 undergraduate distance learning students were surveyed; all from different categories of respondents. The face-to-face meeting was conducted between January and February 2013. The questionnaires were directly administered to the students. They were informed that the main purpose of the study is to compare different blended learning environments to investigate the relationship between Col components, and perceived learning. They were assured that the anonymity of their responses was guaranteed.

\section{Data Analysis}

To test the research hypothesis, SEM was used as the main technique for analyzing the data and testing the hypothetical model. The reason of using SEM is because it is a more suitable tool to analyze the data which the inter-variable specifies in priory based on the theory (Karami, 2011). Moreover, according to Chin (1998), SEM is a second generation multivariate method that is used to assess the reliability and validity of the model measures and allow simultaneous analysis of all the variables in the model instead of separately.

\section{Results}

The research objective in this study was to determine moderation effects of gender on the relationship between Col and perceived learning in different undergraduate blended learning environments. In order to examine this objective, the following null hypothesis was raised.

Ho: Gender does not moderate the relationship between Col components and perceived learning.

To test this hypothesis, multi-group structural equation modelling analysis was used. Hypothesis in relation to moderating effect of gender is tested by comparing path coefficients between two groups (male and female) by using t-value over 1.96 (over .95\% confidences). The researchers concluded that the coefficients had a moderating effect if $t$-value was higher than 1.96. First, the initial model testing indicated a very good model fit $\left(\mathrm{x}^{2} / \mathrm{df}=1.265\right.$; $\mathrm{GFI}=.973 ; \mathrm{CFI}=.996 ; \mathrm{IFI}=.996 ; \mathrm{TLI}=.994 ;$ and RMSEA=.028). The hypothesis model has been shown in Figure 1. 


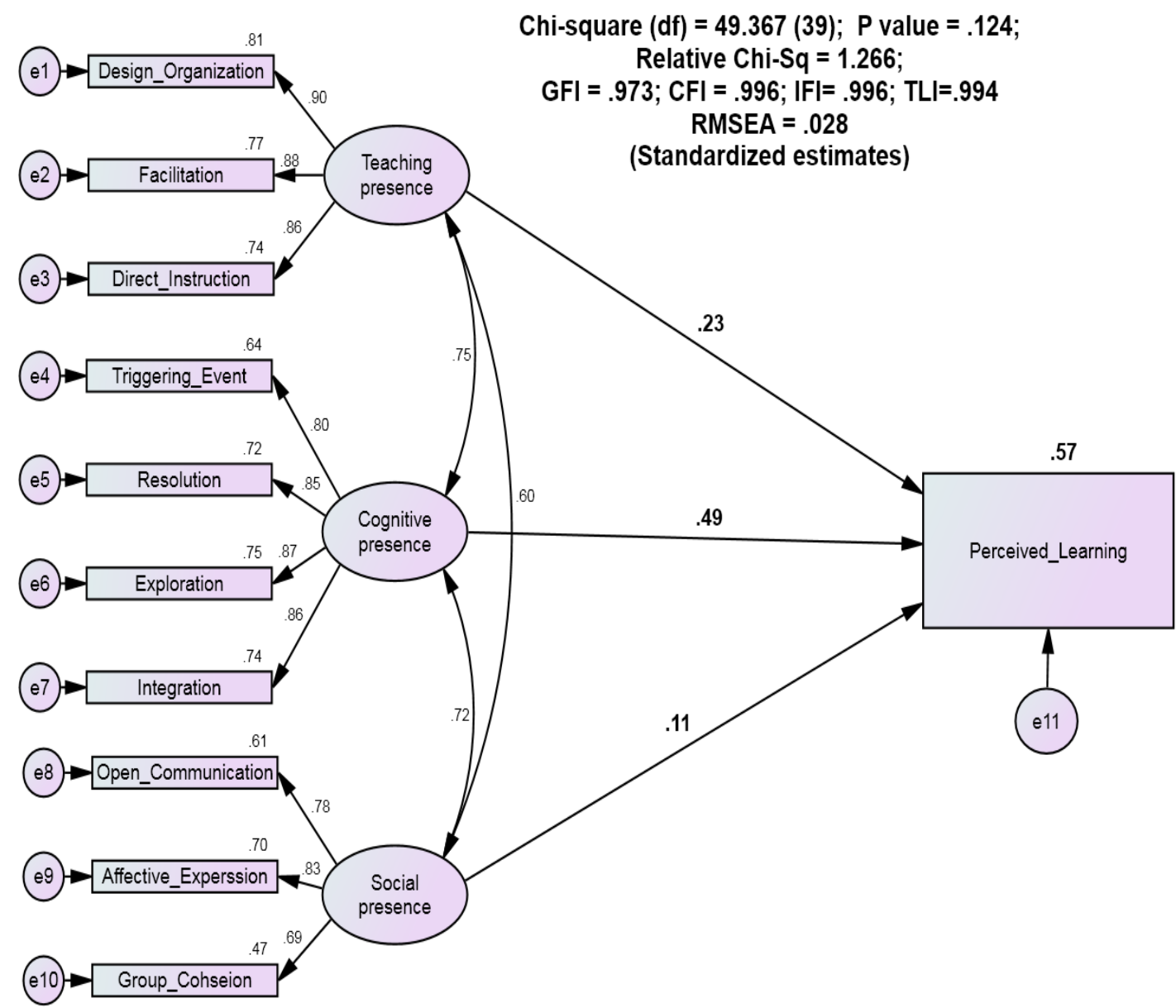

Figure 1. Hypothesized Model

The initial hypothetical Col model (Figure 1) illustrates the relationships among the variables including social presence (open communication, affective expression, and group cohesion), cognitive presence (triggering event, exploration, resolution, and integration) and teaching presence (design and organization, facilitation, and direct instruction).

The next step in checking the structural model process is examining the path estimate from the table of the regression weights in the structural model (Table 1 ) in question, to asses if the differences in both group models are theoretically consistent.

Table1. Regression Weights in the Structural Model

\begin{tabular}{lrrrcccc}
\hline \hline Hypothesized path & & Estimate & S.E. & $\begin{array}{c}\text { Standardized } \\
\text { Regression } \\
\text { Weights }\end{array}$ & C.R. & p \\
\hline Perceived Learning & Teaching Presence & 1.264 & .362 & .229 & 3.491 & .000 \\
Perceived Learning & Cognitive Presence & 3.087 & .528 & .487 & 5.848 & .000 \\
Perceived Learning & Social Presence & 1.098 & .683 & .108 & 1.606 & .108 \\
\hline \hline
\end{tabular}

Nevertheless, Tables 2 and 3 show that the chi-square differences of variant and invariant models are statistically significant $\left(\mathrm{x}^{2}=165.485-101.737=63.749 ; \mathrm{df}=105-78=27 ; \mathrm{p}<0.005\right)$. 
Table 2. CMIN in the Structural Model

\begin{tabular}{lrrrrc}
\hline Model & NPAR & CMIN & DF & p & CMIN/DF \\
\hline Unconstrained/variant & $\mathbf{5 4}$ & $\mathbf{1 0 1 . 7 3 7}$ & $\mathbf{7 8}$ & $\mathbf{. 0 3 7}$ & $\mathbf{1 . 3 0 4}$ \\
Measurement weights & 44 & 107.369 & 88 & .079 & 1.220 \\
Structural covariances & 38 & 120.744 & 94 & .033 & 1.285 \\
Measurement residuals/invariant model & $\mathbf{2 7}$ & $\mathbf{1 6 5 . 4 8 5}$ & $\mathbf{1 0 5}$ & $\mathbf{. 0 0 0}$ & $\mathbf{1 . 5 7 6}$ \\
Saturated model & 132 & .000 & 0 & & \\
Independence model & 22 & 2654.476 & 110 & .000 & 24.132 \\
\hline \hline
\end{tabular}

Table 3. Nested Model Comparisons Assuming Model Unconstrained/Variant to be Correct

\begin{tabular}{llrr}
\hline \hline Model & DF & CMIN & $p$ \\
\hline Invariant & 27 & 63.749 & .000 \\
\hline \hline
\end{tabular}

Hence, it can be concluded that the differences between two models are statistically significant. It means that there are differences between two groups of students (male and female). However, to understand the amount of differences, the researcher should compare male and female models separately. Figures 2 and 3 illustrate both models.

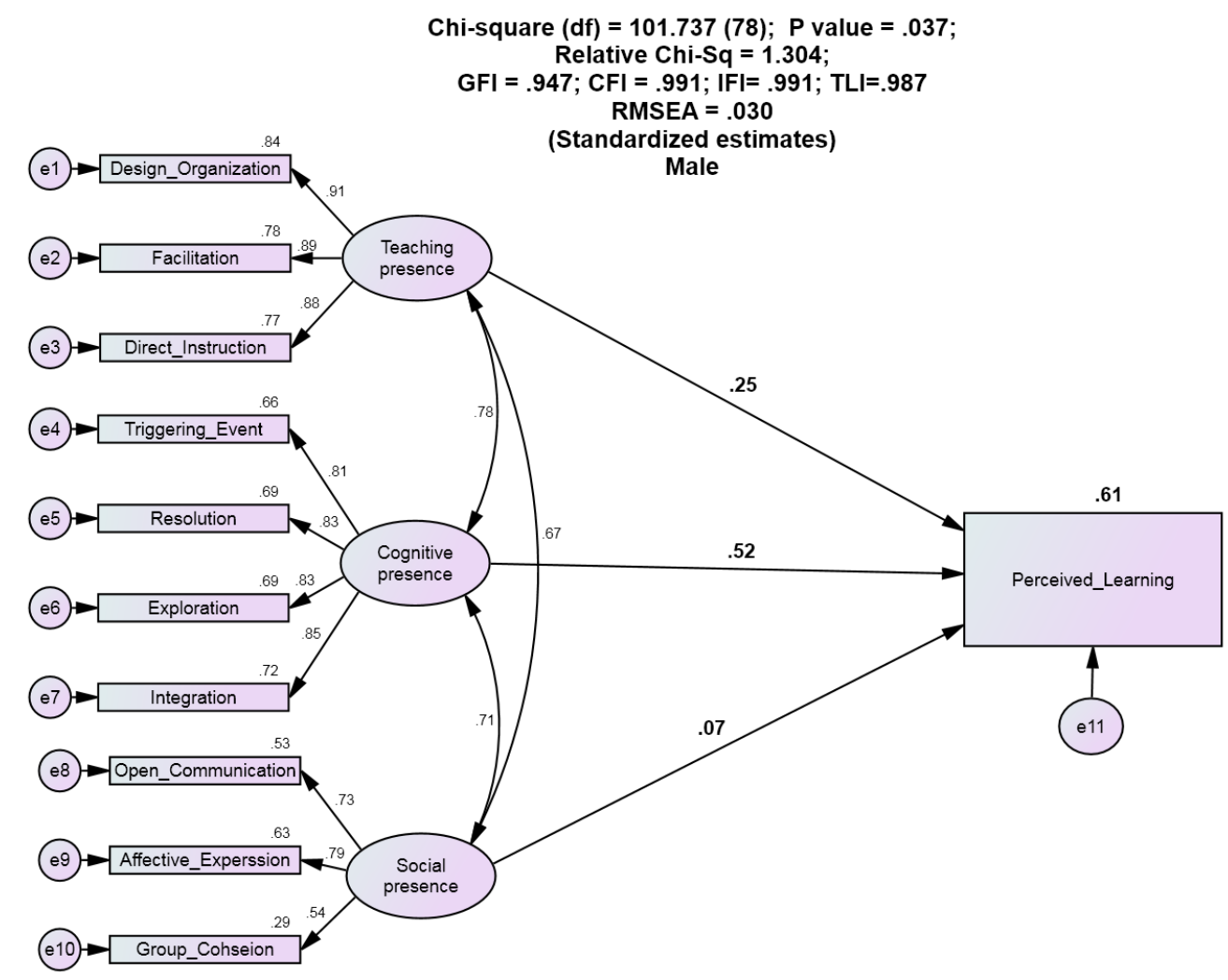

Figure 2. Hypothesized Model (Male) 
Table 4. Regression Weights: (Male - Unconstrained)

\begin{tabular}{lrrrrrrr}
\hline \hline Hypothesized path & & Estimate & S.E. & $\begin{array}{c}\text { Standardized } \\
\text { Regression } \\
\text { Weights }\end{array}$ & C.R. & p \\
\hline Perceived Learning & Teaching presence & 1.306 & .618 & .251 & 2.112 & .035 \\
Perceived Learning & Cognitive presence & 3.223 & .839 & .518 & 3.840 & .000 \\
Perceived Learning & Social presence & .857 & 1.443 & .070 & .594 & .552 \\
\hline \hline
\end{tabular}

To test the moderating effect the researcher was looking for in the significant differences in the two models to support the hypothesis of differences in the path estimate. Tables 4 and 5 show the path estimates of two groups (Male and Female).

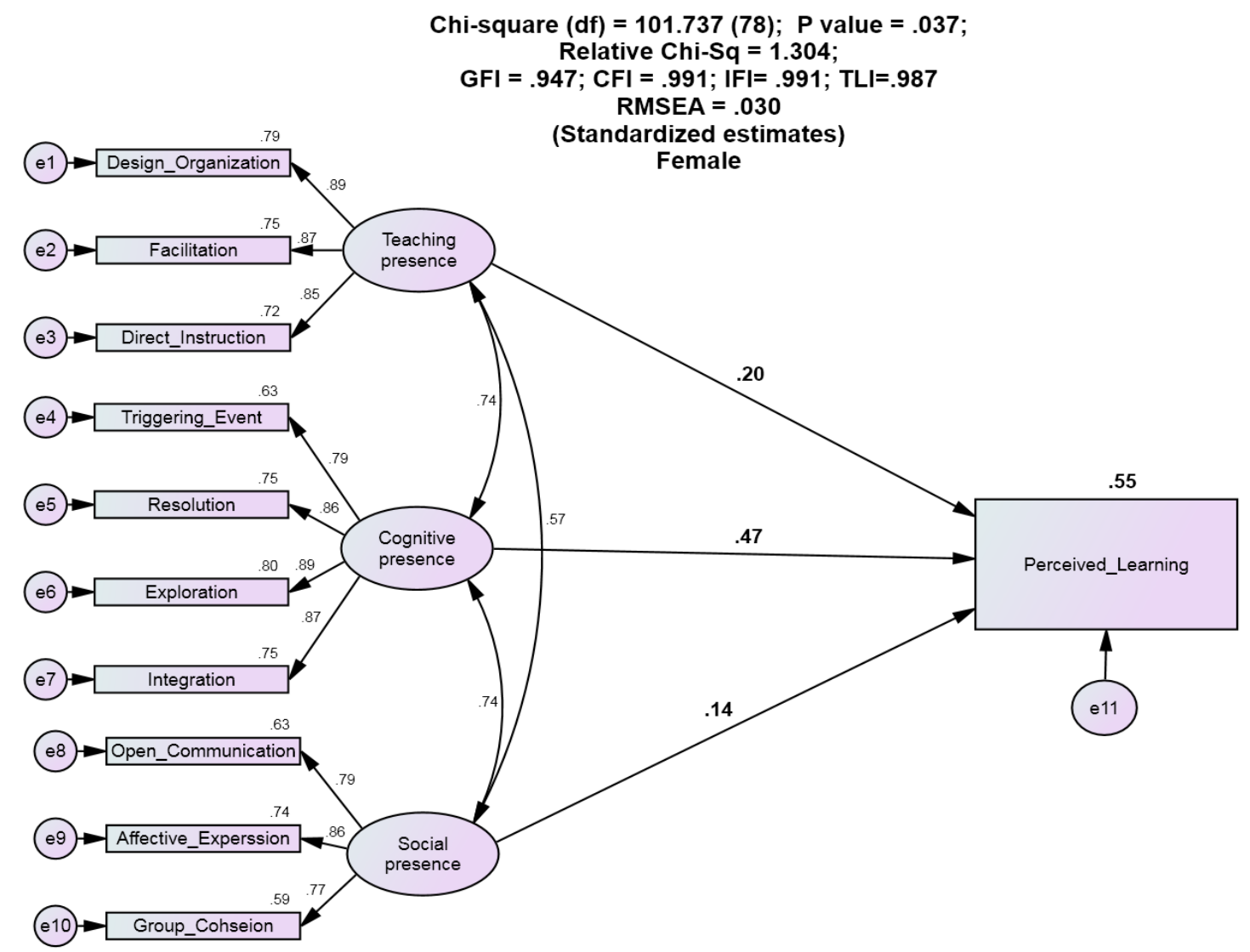

Figure 3. Hypothesized Model (Female)

Table 5. Regression Weights: (Female - Unconstrained)

\begin{tabular}{lcccccc}
\hline \hline Hypothesized path & & Estimate & S.E. & $\begin{array}{c}\text { Standardized } \\
\text { Regression Weights }\end{array}$ & C.R. & P \\
\hline Perceived Learning & Teaching presence & 1.184 & .476 & 2.488 & .204 & .013 \\
Perceived Learning & Cognitive presence & 3.022 & .688 & 4.394 & .472 & .000 \\
Perceived Learning & Social presence & 1.262 & .779 & 1.621 & .137 & .105 \\
\hline \hline
\end{tabular}


Tables 4 and 5 show both $p$-values for male and female are the same although the size of $p$ value for both groups are different, (Male: 0.035; 0.000 and 0.552 and Female: 0.013; 0.000 and 0.105$)$. According to Hair et al. (2010) a variable can play moderating role when it meets at least one of following two conditions:

(1) The direction of correlations is different (one of the relationships is positive and other is negative).

(2) When the $p$-value is different for two groups.

Based on the above conditions, $p$-value for both groups is the same and the directions of the relationships are the same as well (both positive). Hence, it can be concluded that none of the conditions were met. Then, the gender does not moderate the relationship between Col and perceived learning in undergraduate blended learning programs. Therefore, this study failed to reject the null hypothesis, and rejected the alternative hypothesis that gender moderates the relationship between Col components and perceived learning.

Overall, in order to test influences of the gender on the relationship between Col and perceived learning, results of the study showed that gender does not significantly moderate the relationship between Col components and perceived learning. Hence, the finding that gender also does not significantly moderate the relationship between Col and perceived learning. Therefore, the corresponding research hypothesis was not supported.

\section{Discussion}

This study concluded that there are statistically significant differences between Col components and perceived learning of male and female students in three different blended learning environments but these differences are not enough to moderate gender in the relationship between Col and perceived learning. Despite that the literature has suggested that there are differences in Col components. Shea et al., (2006) have found that gender as a significant predictor of learning community. Other studies highlight the role of gender as a link between $\mathrm{Col}$ and perceived learning. This study is in response with Garrison et al, (2010) who suggest that there is a need to determine moderation effects of gender in the relationship between Col elements and perceived learning, The finding of the study is in line with (Shea \& Bidjerano, 2009b; Garrison et al., 2010) the predicted effect of gender on each of the presences and was not confirmed. It is possible that there are no differences across gender reported here as an artefact of the individualization available in a blended learning environments. Further exploration is required concerning this relationship.

In contrast to the findings of the current study, Ruhlandt (2010) stated that statistically significant results were found when Col presences were evaluated between male and female students. Moreover, she found that female students had higher mean scores on teaching presence and cognitive presence than male students. However, male students had higher mean scores on social presence. Other scholars identified that female learners appear to have a higher level of sense of community than male learners (Rovai \& Baker, 2005; Shea, 2006). Since, undergraduate students in blended learning environment with more face-to-face session, reported higher mean scores for all the presences, the difference in the mean scores could be due to the mode of delivery rather than gender. However, more research on this topic is needed. Therefore, this is an important issue for future research. 
Overall, gender did not play its moderation role in the relationship between Col and perceived learning in different blended learning environments. This could be explained from the equilibrium theory which was an assumption to explain how students balance the communicator behavior; and female students engage more in online communicative and collaborative learning (Abbot et al., 2007).

The results of the study also showed that there is relationship between all components and indicators of $\mathrm{Col}$ in the blended learning environments. The finding shows that $\mathrm{Col}$ is a useful theoretical tool to understand the relationships between social, teaching, and cognitive presences and their indicators especially in blended learning environments. As can be seen from the representation, the model hypothesizes that all presences including social, cognitive, and teaching presence will be correlated to one another. This study confirms these relationships. In this regard, the structural equation model predicting a correlation between Col components fits the data presented in this study. One possible reason for these results could be that because the three elements of Col (social, cognitive, and teaching presences) and their indicators are independent and supportive of each other, during a learning experience as well as they are essential elements of successful learning. Another reason could be that Col with it indicators assumes that learning occurs through the interaction of three core elements and their indicators. Moreover, Garrison (2003) claimed that successful learning experience is related with balance of Col elements.

As mentioned above, the findings of this part of the current study provide support for the theoretical predictions of Col framework. Based on the framework and previous research, there is evidence that the three presences are interconnected and influence each other in the hypothesized manner. That is, it was shown through students' perceptions that teaching presence directly influences the perception of social and cognitive presence. Perceptions of social presence also significantly predict perceptions of cognitive presence. Therefore, the finding reinforces the central role of three presences to establishing and sustaining a blended learning environment and realizing intended students' learning.

The finding of the study was also supported by previous studies. For example, Maddrell (2011) found that there is strong correlation among the social, teaching, and cognitive presence which suggested the subscales and their indicators are not independent. Meanwhile, research examining the survey used in this study suggested that it is a valid measure of the students' perception of social, teaching, and cognitive presence and their indicators (Arbaugh et al., 2008; Garrison et al., 2010).

The results of the study confirm the agreement that Col elements are necessary for developing an engaging learning experience and lead to the accomplishment of learning objectives (Garrison et al., 2000). In this regards, the present findings seem to be consistent with other research which found that Col presences are key factors in creating an effective learning environment for blended learning (Akyol \& Garrison, 2011; Carlon et al., 2012; Garrison et al., 2010; Ozturk, 2012). This also accords with the researcher's earlier observations, which showed that the presences help to improve the blended learning environment through directs of attention to the process of constructing and confirming deep and meaningful learning experiences (Vaughan, 2010).

An interesting result was the relationship between students' perceived level of Col and their perceived learning. Given that all findings related to learning were high, it can be concluded that the community of inquiry is strongly associated with high levels of perceived learning. It is 
suggested that Col and it components are associated with high perceptions of students' learning in the blended learning environments (Akyol, Garrison, 2011; Akyol, Vaughan, \& Garrison, 2011).

\section{Conclusion}

The findings of the study have shown that although differences between the two groups of undergraduate students (male and female) were statistically significant, the amount of differences were not enough to moderate the relationship between Col components (presences) and perceived learning in undergraduate blended learning environments. In this part of the study, the researcher has not found what he has expected. Initially, it is thought that gender may moderate the relationship between Col components (presences) and perceived learning.

Based on this evidence the research has hypothesized gender is a moderator in perceived learning and Col components. However, the findings indicate that differences between the two groups of undergraduate students (male and female) were statistically significant. Therefore, this perceived relationship has been shown in previous research to be crucial to reach resolution and achieve students' perceptions of a successful learning experience.

Based on the literature that confirmed differences between gender in online and blended learning environments (Rovai \& Baker, 2005) it was reasonable to believe that engagement in a community of inquiry could vary across gender. For this reason, the researcher hypothesized that gender may moderate the relationship between Col and perceived learning in blended learning environments. The model proposed in this study suggests that gender doesn't moderate the relationship between Col and perceived learning in the blended learning environments. Hence, instructional designers and instructors may provide good opportunities for male and female students in blended learning environments to meet their educational needs. The gender differences in the social, teaching, and cognitive presences mean scores indicate that male and female students do not have different perceptions.

Future research should focus on other demographical variables such as age group and level of study to investigate the moderation effect of these variables on the relationship between Col and perceived learning of both undergraduate and postgraduate students in blended learning environments.

\section{References}

Abbot, G., Bienvenue, L., Damarin, S., Kramarae, C., Jepkemboi, G., \& Strawn, C. (2007). Gender equity in the use of educational technology. In S. Klein (Ed.), Handbook for achieving gender equity through education (pp. 191-214). Mahwah, NJ: Lawrence Erlbaum.

Akyol, Z. \& Garrison, D. (2011). Understanding cognitive presence in an online and blended community of inquiry: Assessing outcomes and processes for deep approaches to learning. British Journal of Educational Technology, 42(2), 233-250. 
Akyol, Z., Vaughan, N., \& Garrison, D. (2011). The impact of course duration on the development of a community of inquiry. Interactive Learning Environments, 19(3), 231246.

Alavi, M., Marakas, G., \& Yoo, Y. (2002). A comparative study of technologies for distance learning. Information Systems Research, 13(4), 404-415

Arbaugh, J., Cleveland-Innes, M., Diaz, S., Garrison, D., Ice, P., Richardson, J., \& Swan, K. (2008). Developing a community of inquiry instrument: Testing a measure of the community of inquiry framework using a multi-instructional sample. Internet and Higher Education, 11(2), 133-136

Arbaugh, J. B. (2007). An empirical verification of the community of inquiry framework. Journal of Asynchronous Learning Networks, 11(1), 73-75

Astleitner, H., \& Steinberg, R. (2005). Are there gender differences in web-based learning? An integrated model and related effect sizes. AACE Journal, 13 (1), 47-63

Bentz, D. (2009). Online and face-to-face classes: A comparative analysis of teaching presence and instructor satisfaction (Unpublished doctoral dissertation).

Carlon, S., Bennett-Woods, D., Berg, B., Claywell, L., LeDuc, K., Marcisz, N., Mulhall, M., Noteboom,T., Snedden, T., Whalen, K., \& Zenon, L. (2012). The community of inquiry instrument: Validation and results in online health care disciplines. Computers \& Education, 59, $215-221$.

Chin, W. (1998). The partial least squares approach for structural equation modeling. In G. A. Marcoulides (Ed.), Modern methods for business research (pp. 295-336). Mahwah, NJ: Lawrence Erlbaum Associates.

Corrallo, S. (1994). The progress of a study identifying the speaking and communication skills of graduate student. 1994 NCA summer conference proceedings and prepared remarks: Assessing college students' competency in speech communication. Armadale, VA.

Dewey, J. (1938). Experience and education. New York: Collier Books.

Garrison, D., \& Arbaugh, J. (2007). Researching the community of inquiry framework: Review, issues, and future directions. The Internet and Higher Education, 10(3), 157-172.

Garrison, D. \& Vaughan, N. (2008). Blended learning in higher education: Framework, principles, and guidelines. San Francisco, CA: John Wiley \& Sons.

Garrison, D., Cleveland-Innes, M., \& Fung, T. (2010). Exploring causal relationships among teaching, cognitive and social presence: Student perceptions of the community of inquiry framework. Internet and Higher Education, 13(1-2), 31-36.

Garrison, D. R. \& Anderson, T. (2003). E-learning in the 21st century: A framework for research and practice. London: Routledge.

Garrison, D. R,. Anderson, T., \& Archer, W. (2000). Critical inquiry in a text-based environment: Computer conferencing in higher education. The Internet and Higher Education, 2(2-3), 87-105.

Garrison, D. R. (2003). Cognitive presence for effective asynchronous online learning: The role of reflective inquiry, self-direction and metacognition. In J. Bourne \& J. Moore (Eds.), Elements of quality online education: Practice and direction (Vol. 4). Needham, MA: The Sloan Consortium. 
Garrison, D. R. (2007). Online community of inquiry review: Social, cognitive, and teaching presence issues. Journal of Asynchronous Learning Networks, 11(1), 61-72

Gibson, A., Ice, P., Mitchell, R., \& Kupczynski, L. (2012). An inquiry into relationships between demographic factors and teaching, social, and cognitive presence. Internet Learning, 1(1), 7-17.

Gunn, C., McSporran, M., Macleod, H., \& French, S. (2003). Dominant or different? Gender issues in computer supported learning. Journal of Asynchronous Learning Networks, 7(1), 14-30

Hair, J., Black, W., Babin, B., \& Anderson, R. (2010). Multivariate data analysis (7th ed.). Upper Saddle River, NJ: Prentice Hall

Hannafin, M. J., Hill, J., Oliver, K. M., Glazer, E. M., \& Sharma, P. (2003). Cognitive and learning factors in Web-based distance learning environments. In M. G. Moore \& W. G. Anderson (Eds.), Handbook of distance education (pp. 245-260). Mahwah, NJ: Lawrence Erlbaum Associates

Karami, R. (2011). Factor infusing achievement motivation in leadership role of extension agents in Iran (Unpublished doctoral dissertation). Universiti Putra Malaysia, Malaysia.

Kim, J. (2011). Developing an instrument to measure social presence in distance higher education. British Journal of Educational Technology, 42(5), 763-777

Krish, P., Maros, M., \& Stapa, S. (2012). Sociocultural factors and social presence in an online learning environment: GEMA Online. ${ }^{\mathrm{TM}}$ Journal of Language Studies, 12(1), 201-213

Lewis, J. (2011). The computer ate my classroom: Assessing student interactions, perceived learning, and satisfaction in online community college career technical education courses. ProQuest LLC (Unpublished doctoral dissertation). The University of Southern Mississippi.

Lord, G. \& Lomicka, L. (2008). Blended learning in teacher education: An investigation of classroom community across media. Contemporary Issues in Technology and Teacher Education, 8(2), 158-174.

Lu, J., Yu, C. S., \& Liu, C. (2003). Learning style, learning patterns and learning performance in a WebCT-based MIS course. Information \& Management, 40, 497-507

Maddrell, D. (2011). Community of inquiry framework and learning outcomes (Unpublished doctoral dissertation). Old Dominion University. Norfolk, Virginia, United States.

Ong, C. H. \& Lai, J. Y. (2006). Gender differences in perceptions and relationships among dominants of e-learning acceptance. Computers in Human Behavior, 22(5), 816-829

Ozturk, E. (2012). An adaptation of the community of inquiry index: The study of validity and reliability, Elementary Education Online, 11(2), 408-422.

Patrizi, A. (2010). The impact of online faculty characteristics on student satisfaction via the community of inquiry framework. ProQuest LLC (Unpublished doctoral dissertation). TUI University.

Price, L. (2006). Gender differences and similarities in online courses: Challenging stereotypical views of women. Journal of Computer Assisted Learning, 22, 349-359 
Rovai, A, Wighting, M, \& Lucking, R. (2004). The classroom and school community inventory: Development, refinement, and validation of a self-report measure for educational research. Internet and Higher Education, 7(4), 263 - 280

Rovai, A, Wighting, M., Baker, J., \& Grooms, L. (2009). Development of an instrument to measure perceived cognitive, affective, and psychomotor learning in traditional and virtual classroom higher education settings. Internet and Higher Education, 12, 7-13

Rovai, A. \& Baker, J. (2005). Gender differences in online learning: Sense of community, perceived learning, and interpersonal interactions. The Quarterly Review of Distance Education, 6(1), 31-44.

Ruhlandt, R. (2010). Differences in retention, social presence, cognitive presence, and teaching presence in fully online and blended courses. ProQuest LLC (Unpublished doctoral dissertation). Regents University.

Shea, P., Sau-Li, C., \& Pickett, A. (2006). A study of teaching presence and student sense of learning community in fully online and web-enhanced college courses. The Internet and Higher Education, 9(3), 175-190

Shea, P. (2006). A study of students' sense of learning community in online environments. Journal of Asynchronous Learning Networks, 10(1), 35-44

Shea, P. \& Bidjerano, T. (2009b). Community of inquiry as a theoretical framework to foster "epistemic engagement" and "cognitive presence" in online education. Computers and Education, 52(3), 543-553.

Sullivan, P. (2001). Gender differences and the online classroom: Male and female college students evaluate their experiences. Community College Journal of Research and Practice, 25(6), 805-818.

Swan, K. \& Ice, P. (2010). The Community of Inquiry framework ten years later: Introduction to the special issue. Internet and Higher Education, 13(1-2), 1-4.

Taplin, M. \& Jegede, O. (2001). Gender differences in factors influencing achievement of distance education students. Open Learning, 16(2), 133-154

Tu, C. (2002). The measurement of social presence in an online learning environment. International Journal on E-learning, 1(2), 34-45

Vaughan, N. (2010). Designing for a blended community of inquiry. In T. Joutsenvirta \& L. Myyry (Eds.) Blended Learning in Finland. Helsinki: University of Helsinki.

Yukselturk, E. \& Bulut, S. (2007). Predictors for student success in an online course. Educational Technology \& Society, 10(2), 71-83

Yukselturk, E. \& Bulut, S. (2009). Gender differences in self-regulated online learning environment. Educational Technology \& Society, 12(3), 12-22.

Correspondence: Rouhollah Khodabandelou, Doctoral Student, Department of Educational Technology, Faculty of Educational Studies, Universiti Putra Malaysia, Serdang, Selangor, Malaysia. 